\title{
LA ATRIBUCIÓN PREFERENTE DE LA VIVIENDA FAMILIAR AL CÓNYUGE SUPÉRSTITE EN EL DERECHO DE QUÉBEC
}

\section{Ernest Caparros}

Profesor de Derecho Civil

Universidad de Ottawa (Canadá)

\section{Introducción}

Parece necesario comenzar presentando las facetas múltiples de la vivienda familiar en el ordenamiento de Québec ${ }^{1}$. Eso nos permitirá centrarnos en la normativa específica que considera la adjudicación preferente de la vivienda familiar en caso de fallecimiento de uno de los cónyuges, una eventual, en la reglamentación del régimen legal supletorio de la société d'acquêts, la otra más real, a pesar de ser aleatoria, en el contexto preciso de la sucesión.

\section{Las facetas de la vivienda familiar}

En el derecho actual de Québec, la vivienda familiar es una realidad con numerosas facetas jurídicas, una especie de diamante bien tallado, si el legislador hubiera realizado una verdadera obra de orfebrería legislativa. Desgraciadamente, esa realidad con tantas facetas aparece a veces más bien como un dragón con múltiples cabezas, a consecuencia de las incertidumbres que provoca y las imprecisiones de los textos legislativos y de sus interpretaciones jurisprudenciales y doctrinales.

Establezcamos brevemente el contexto jurídico antes de adentramos en la materia de nuestro estudio. Así pues, el Código reglamenta la vivienda familiar bajo varios conceptos y en distintas partes de su reglamentación.

\footnotetext{
Texto preparado como resultado del Proyecto de Incentivo a la Cooperación Internacional complementario al la investigación financiada por el Concurso Regular de Fondecyt ( $N^{2} 1000480$, del 2000) titulado «El derecho de adjudicación preferente en favor del cónyuge sobreviviente en los bienes del causantex.

${ }^{1}$ Hemos criticado ese comportamiento legislativo en varias circunstancias: cf. E. CAPARROS, "Le patrimoine familial qué bécois: une qualification difficile', Écrits en hommage à Gérard Cornu, Paris, P.U.F., 1994, pp. 51-69, o en (1994) 25 R.G.D. 251-267; ID, "Le patrimoine familial qué bé cois: comme un œuf de coucou dans le nid du Code civil du Québec", dans J. BEAULNE et M. VERWILGHEM (dir.), Points de droit familial/Rencontres universitaires notariales belgo-québécoises, Collection bleu, Montréal, Wilson \& Lafleur Ltée, 1997, pp. 147-168; ID, "La nature juridique commune du patrimoine familial et de la société d'acquêts", (1999-2000) 30 R.G.D.1-60.
} 


\section{En el régimen primario: la protección de la utilización familiar}

En el régimen primario se detalla la protección de la utilización familiar de la vivienda durante el matrimonio (art. 401-413), aunque ese régimen de protección aparezca más teórico que real a consecuencia de los avisos o de la inscripción necesaria en los registros oportunos para que la protección sea verdaderamente eficaz. También se prevé en ese contexto, en casos de ruptura de la vida común por separación de cuerpos, o de anulación del matrimonio o divorcio civil, la posibilidad de la adjudicación judicial del contrato de inquilinato al cónyuge no inquilino ${ }^{3}$. Esas disposiciones determinan igualmente la forma de poder adjudicar a uno de los cónyuges la propiedad o un derecho real de uso de los muebles del otro, si servían a la familia, así como el uso de la residencia familiar al cónyuge a quien se confía la custodia de un hijo. De todas formas, y salvo en el último supuesto, esas adjudicaciones se hacen en pago de un derecho que ha de existir, puesto que el mismo Código exige el pago del excedente o diferencia de precio (soulte $)^{5}$. No se puede olvidar que esas normas aparecieron en el Code civil du Québec, en la versión de 1980, como uno de los modos de pago de la prestación compensatoria que se introdujo entonces en el Código ${ }^{6}$.

\section{En el patrimonio familiar: el valor económico de las viviendas}

En el contexto del régimen legal imperativo, el "patrimoine familial», el concepto de residencia principal aparece en la reforma de $1989^{7}$, para terminar en el Código actual como residencias de la familia ${ }^{8}$. Sin embargo, en este contexto se tiene en cuenta el valor económico de las residencias de la familia y de los muebles que las

\footnotetext{
${ }^{2}$ Cf. art. 403 C.c.Q., aviso escrito al propietario del inmueble en el que se encuentra la vivienda alquilada; art. 404 y 405 C.c.Q., inscripción registral de la declaración de residencia familiar contra el inmueble propiedad de uno de los cónyuges donde se encuentra esa vivienda; art. 407 C.c.Q., sobre las formalidades de la inscripción. Las críticas de esa pseudo-protección sc hicieron desde los estudios de los primeros proyectos, cf. E. CAPARROS, "Remarques sur le Bill 10, loi concernant les régimes matrimoniaux", (1969) 10 C. de D. 496-507; ID., "Remarques sur l'avant-projet de protection de la résidence familiale", (1971) 12 C. de D. 316-320; ID, "Le logement et la famillem, (1982) 13 R.G.D. 313-336, o en TX DE L'ASS. H. CAPITANT, Le droit au logement (Journées Mexicaines), T. XXXIII, 1982, Paris, Economica, 1984, pp. 397-419; G. DALLAIRE, "La protection de la résidence familiale - la nouvelle loi du Québec: un échec?», Le Devoir, Montréal, 22 avril 1982, p. 7.

${ }^{3}$ Cf. art. 409 C.c.Q

${ }^{4}$ Cf. art. 410 C.c.Q.

${ }^{5}$ Cf. art. 411 C.C.Q

6

Hemos estudiado esa noción y sus primeras aplicaciones jurisprudenciales en E. CAPARROS, "La prestation compensatoire dans le droit civil nouveau", (1983) 13 R.G.D.131-165; ID, Les régimes matrimoniauxau Québec, $3^{2}$ edición, $2^{3}$ reimpresión corregida, Collection bleu, Montréal, Wilson \& Lafleur Ltée, 1988, $n^{05}$ 67-107, pp. 55, 86 [citaremos como: CAPARROS, $3^{e}$ éd.]. Con algunas modificaciones se encuentra ahora reglamentada en los art. $427-430$ C.c.Q.

${ }^{7}$ Cf. art. 462.2 C.c.Q. $/ 89$

${ }^{8}$ Cf, art. 415 C.c.Q.
} 
guarnecen y ornamentan con objeto de establecer el crédito de igualación en el patrimonio familiar. No se trata pues de una adjudicación de la residencia o de los muebles, sino de sumar unos valores que permitirán determinar, tras la sustracción de las deudas y conceptos previstos, la cantidad en numerario de ese crédito y el cónyuge acreedor, aunque se contemple también la posibilidad de que el tribunal adjudique algunos bienes en pago del crédito de participación, respetando ciertas condiciones ${ }^{9}$.

\section{En la société d'acquêts: la posible adjudicación preferente en caso de muerte}

En el régimen legal (ahora supletorio) de "société d'acquêts", que llamaremos sociedad de gananciales para mayor facilidad, (aunque hay que evitar que se confunda con regímenes de gananciales de España o de otros países de habla hispana con regímenes similares), apareció ya en 1969 una auténtica adjudicación preferente de la residencia familiar, dentro de un conjunto más amplio de bienes familiares. En efecto, el cónyuge supérstite podía exigir que la residencia familiar se incluyera en su lote de partición de la indivisión de los gananciales del de cuis o de los suyos, siempre que el inmueble estuviera incluido en una de las masas de gananciales ${ }^{10}$. Cuando se sancionó el nuevo Code civil du Québec en 1980, que no contenía más que el libro II «De la famillle» y que se puso en vigor parcialmente, la misma disposición del artículo $1257 \mathrm{C}$ C.c.B.C. se mantuvo sin variaciones esenciales, salvo que se había dividido en dos artículos, los 514 y 515. No se alteró el derecho del cónyuge sobreviviente de solicitar la adjudicación preferente de la vivienda y otros bienes familiares, siempre que esos bienes fueran gananciales, en la partición de la indivisión del cónyuge difunto, manteniendo la obligación de pagar el excedente de su parte. La nefasta reforma legislativa de 1989 provoca un cambio radical en la naturaleza de la société d'acquêts ${ }^{11}$. En efecto, las indivisiones de gananciales que se constituían al disolverse el ré gimen desaparecen y ese derecho real se le trueca a cada cónyuge por un derecho de crédito no garantizado, para igualar así este régimen con el del patrimoine familial. Ahora bien, parece que el legislador ha transformado la naturaleza jurídica del régimen supletorio legal por casualidad, como el famoso burro flautista de la fábula de Samaniego, pues modifica el artículo 514 precisando que la partición que se lleva a cabo es la del valor neto de la masa de gananciales (el artículo 514 de 1980 hablaba de la partición de la masa de gananciales según las reglas de los repartos entre coherederos), sin retocar siquiera el artículo 515 que reconoce al sobreviviente el derecho de exigir que se incluya en su lote la vivienda y otros bienes familiares, aunque tenga que pagar el excedente de su parte.

\footnotetext{
${ }^{9}$ Cf. art 420 C.c.Q

${ }^{10}$ Cf. art 1267 c C.c.B.C.; este artículo se mantuvo en vigor entre 1970 y 1981, cuando el Code civil du Québec de 1980 comenzó a regir una parte del Derecho de familia.

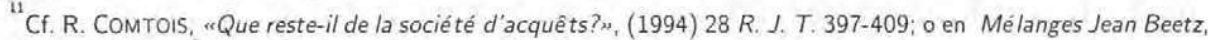
Montréal, Les Éditions Thémis, 1995, pp. 187-197.
} 
La contradicción es flagrante y esa situación en la que el legislador ha puesto en evidencia la ignorancia de su proprio ordenamiento ha sido mantenida en el código hasta que entró en vigor el actual, el 1 de enero de 1994. Al transvasarlo al nuevo código, el contenido del artículo 515, que lleva ahora el número 482, se ha limpiado de los errores más groseros, pero sigue siendo un testigo indiscreto de un legislador incompetente. Ya estudiaremos más en detalle estos temas.

\section{La aleatoria adjudicación preferente por vía sucesoria}

En fin, para concluir este rápido periplo, en el Derecho de sucesiones del nuevo Código, se establecen las normas que reconocen al cónyuge sobreviviente, cuando sea heredero, el derecho de exigir una atribución preferente de la vivienda familiar, cuando esta se encuentre en la masa indivisa, al llevar a cabo la partición de la herencia, siempre a cargo del pago del excedente de su parte, si se aplica al caso ${ }^{12}$.

\section{Síntesis}

He aquí pues el panorama general de la normativa del Code civil du Québec tocante a la vivienda familiar. Se desprende fácilmente que la perspectiva desde la que se contempla esa realidad y los objetivos que la norma persiga conducen a interesarse diversamente de la vivienda y de otros bienes familiares. Así pues, las medidas jurídicas del régimen primario buscan (bien que de forma incompleta y precaria ${ }^{13}$ ) la protección del uso de la vivienda y otros bienes familiares (como los muebles) y pueden proteger a la familia durante el matrimonio, pero no tienen impacto directo sobre la propiedad de esos bienes, auque su titular pueda ver su derecho de disposición limitado de alguna forma. Por otra parte, cuando esos bienes familiares se toman en consideración para establecer el valor del patrimonio de cada uno de los cónyuges con vistas a establecer una cuota y un crédito de igualación, como es el caso en el régimen legal imperativo, o sea el patrimoine familial, entonces se comprende que se desee incluir todas las viviendas y todos los bienes familiares, siempre y cuando, claro está, respondan a la calificación necesaria de bienes gananciales. La vivienda y otros bienes familiares podrán ser utilizados como modo de pago del crédito de igualación, pero no se trata de una adjudicación preferente stricto sensu puesto que no hay partición de una indivisión

${ }^{12}$ Cf. art.856 C.c.Q. Estas cuestiones han sido estudiadas por G. BRIËRE, Le nouveau droit de successions, $2{ }^{\mathrm{e}}$ éd., Collection bleue, Montréal, Wilson \& Lafleur Ltée, 1997, $n^{05} 724-734$, pp. 462-467; ID, Les successions, Cowansville, Les Éditions Yvon Blais, inc., 1994, nos 845-856, pp. 970-986; J. BEAULNE, La liquidation des successions sous le Code civil du Québec, Ré pertoire de droit/ n.s., Montréal, Chambre des notaires du Québec. $1996, n^{\text {ss }} 452-456$, pp. 122-123.

${ }^{13} \mathrm{Cf}$

Cf. S. GRONDIN, "La protection de la résidence familiale en droit québécois", dans Points de doit familial / Rencontres universitaires notariales belgo-québécoises, J. EtiAULNE et M. VERWILGHEN (dir.), Collection bleue, Montréal, Wilson \& Lafleur Ltée, 1997, 79-104; CAPARROS, 3éd., nos 50-60, pp. 34-47. 
sucesoria. También puede entrar en linea de cuentas la vivienda u otros bienes familiares como modo de pago de una prestation compensatoire. Tampoco se trata entonces de una adjudicación preferente stricto sensu, sino de la consideración de la vivienda como moneda de pago en bienes del crédito de un cónyuge contra el otro en un contexto preciso de enriquecimiento injusto, que eso es en el fondo la prestación compensatoria del Derecho de Québec, una modalidad de enriquecimiento injusto como lo ha afirmado la Corte Suprema ${ }^{14}$.

Quedan pues dos conjuntos de normas en las que se puede considerar que hay o puede haber una adjudicación preferente de la vivienda familiar al cónyuge sobreviviente. La primera, que quedaba muy clara cuando se introdujo en el Code civil du Bas Canada en 1970, se ha ido obscureciendo en las últimas reformas, me refiero a la adjudicación de la vivienda y otros bienes familiares en el contexto de la disolución de la société d'acquêts por el fallecimiento de uno de los cónyuges. El segundo conjunto de normas se encuentra en el contexto preciso del derecho sucesorio y ha sido introducido en el ordenamiento de Québec en 1994, al comenzar a aplicarse el nuevo Code civil du Québec. Estudiemos pues ahora estas dos avenidas.

\section{Una adjudicación preferente ilusoria: la société d'acquêts}

Entendámosnos, este título refleja la situación actual, pues cuando este nuevo ré gimen legal comenzó a aplicarse el $1^{\circ}$ de julio de 1970 , con su articulado integrado en el Code civil du Bas Canada, el legislador había sancionado una normativa en la que el cónyuge sobreviviente podía ejercer el derecho de reclamar que se le atribuyera la propiedad de la vivienda familiar (y de otros bienes familiares) en la partición de los gananciales indivisos. Este mismo derecho se mantuvo en 1980 al sancionar el nuevo (ahora viejo) Code civil du Québec, mejorándolo al abolir la necesidad de escoger entre la partición de gananciales y de la herencia. Sin embargo, el legislador deterioró considerablemente ese derecho el $1^{\circ}$ de julio de 1989 al transformar la naturaleza de la sociedad de gananciales a un doble título: primero la relegó al rango de régimen legal supletorio (el patrimonio familiar ocupa el rango de régimen legal imperativo) y en segundo lugar transformó el derecho real de copropiedad que cada cónyuge (o sus herederos) podían ejercer en las indivisiones de gananciales en un derecho de crédito no garantizado. Además hasta que entró en vigor el nuevo Code civil du Québec el $1^{\circ}$ de enero de 1994 el código anterior mantuvo un articulado intrínsecamente contradictorio $^{15}$. Las modificaciones de 1994 no resuelven todos los problemas.

\footnotetext{
${ }^{14}$ CF. M.E.M. C. P.L. [1992] 1 R.C.S. 183, inf. Droit de la famille -594, [1989] R.J.Q. 271; S.P. C. M.R., [1996] 2 R.C.S. 842 .

${ }^{15}$ Comparar en el anexo los art. 514 y 515 C.c.Q. en sus versiones de 1980 y de 1989.
} 
Estudiemos cada una de estas etapas siguiendo el orden cronológico. Cuando se trata de comparar sistemas he considerado siempre útil manifestar claramente los errores de un legislador para evitar, en la medida de lo posible que otros legisladores caigan en los mismos yerros, por aquello de que "un hombre prevenido vale por dos" ${ }^{16}$.

Para facilitar el estudio de estas cuestiones me ha parecido conveniente reproducir en un anexo los artículos de esos códigos que utilizaré en la argumentación. en sus diversas versiones (véase anexo al final).

\section{El dilema impuesto por la reforma de 1970}

Cuando se reforma el Code civil du Bas Canada en 1969 para introducir cambios substanciales tanto en los regímenes económico-matrimoniales ${ }^{17}$ como, en parte en el derecho de sucesorio y de donaciones ${ }^{18}$, se reconoce al cónyuge supérstite un derecho de adjudicación preferente de la vivienda familiar en el art. 1267c. Sin embargo, se modifica igualmente el art. $624 \mathrm{c}$ que regula las opciones del cónyuge sobreviviente en caso de sucesión intestada. Ese artículo reglamentaba la imposibilidad de cumular los derechos sucesorios con los de partición de la comunidad de bienes (que era hasta ese momento el régimen legal), la modificación incluye al cónyuge sobreviviente en sociedad de gananciales, el nuevo régimen legal. Esto tiene como consecuencia que el cónyuge supérstite debía escoger entre su derecho de adjudicación preferente de la vivienda por vía de gananciales y la parte que por herencia intestada le hubiera correspondido. De ahí el dilema.

El artículo 1267c dicta claramente que cuando el régimen de gananciales se disuelve por el fallecimiento o la ausencia de uno de los cónyuges, el otro puede reclamar que se incluya en su parte de gananciales la vivienda y otros bienes familiares. Las condiciones de esa adjudicación preferente son simples: esos bienes reclamados han de ser necesariamente gananciales, la reclamación ha de hacerse en la partición de las indivisiones de los gananciales y si el valor de los bienes así reclamados superan la parte que le correspondía en la partición, el cónyuge sobreviviente ha de pagar el excedente, aunque se puedan establecer modalidades de pago aplazado. Así, si la vivienda es un bien proprio queda excluida de la aplicación de la norma. Igualmente queda excluida

\footnotetext{
${ }^{16}$ Aunque el refranero lo aplica al hombre, pienso yo que la mujer prevenida, con su peculiar intuición, debe valer al menos por cuatro.

${ }^{17}$ Cf. para un estudio sumario de las reformas: E. CAPARROS, "Remarques sur le Bill 10, loi concernant les régimes matrimoniaux", (1969) 10 C. de D. 496-507; ID, "Loi concernant les régimes matrimoniaux", (1970) 11 C. de D. 303-320.

${ }^{18} \mathrm{Cf}$. para un estudio sumario de las reformas: V. NABHAN, "Incidences du Bill 10 sur les droit des donations", (1970) 11 C. de D. $321-329$
} 
esa posibilidad si el cónyuge sobreviviente considera más favorable renunciar a sus derechos en la sociedad de gananciales y optar por su parte en la sucesión intestada.

Conviene subrayar que ese dilema no existía de forma general, pues en Québec las sucesiones intestadas no eran la norma, antes al contrario. En la mayoría de los casos los esposos habían otorgado testamento ${ }^{19}$ y entonces el artículo $624 \mathrm{c}$ no era aplicable. En esos casos, el cónyuge sobreviviente tenía derecho a solicitar que la vivienda familiar se incluyera en su lote, al llevar a cabo la partición de los gananciales sin tener que renunciar a su parte a título de heredero testamentario. Ahora bien, esta norma no permitía un aumento de la parte del cónyuge sobreviviente ni en los gananciales ni en la herencia. Así pues, si el valor de la vivienda sobrepasaba la mitad de los gananciales del difunto, el sobreviviente tenía que pagar el excedente (soulte). Se comprende que esta exigencia de justicia podía crear un obstáculo a la atribución preferente, aunque se preveía la posibilidad de pagos aplazados. De todas formas, cabía la posibilidad que el valor de la mitad de los gananciales del sobreviviente pudiera compensar por el valor del excedente o que su parte de la herencia testamentaria le permitiera pagar ese excedente. Como puede verse, una vez ejercido el derecho de atribución preferente por el cónyuge supérstite y si el valor superaba su parte, este cónyuge debía encontrar la forma de pagar la diferencia.

\section{La posibilidad de acumular derechos: la reforma de 1980}

Cuando el Code civil du Québec de 1980, que no contiene más que le Libro II, comienza su vigencia parcial en dos etapas, la primera el 2 de abril de 1981 y la segunda el $1^{2}$ de diciembre de 1982 , se introducen al mismo tiempo algunas reformas en el Code civil du Bas Canada en el que se contiene la reglamentación de la casi totalidad del derecho civil. Una de esas reformas es la abrogación pura y simple del artículo 624c C.c.B.C. Desaparece pues el dilema mencionado en el párrafo precedente y en todos los casos el cónyuge sobreviviente puede exigir que la vivienda familiar se incluya en su lote de partición de los gananciales, siempre a cargo del pago eventual del excedente del valor de su parte. También se mejora ligeramente en esta reforma la formulación de los artículos a la vez que las disposiciones del antiguo artículo 1267c C.c.B.C. se dividen en dos artículos. Por lo demás, todo sigue sin cambios substanciales.

\footnotetext{
${ }^{19}$ Recordemos que en el derecho de Qué bec existe, desde 1784, por influencia del Derecho Británico, la libertad absoluta de disponer por testamento de sus bienes sin restricción alguna, sin embargo, la reforma de 1989 ha introducido algunas limitaciones como consecuencia de la imposición legal del patrimonio familiar. Para un estudio de la evolución de este derecho ver G. BRIÉRE, Le nouveau droit de successions, $2^{\mathrm{e}}$ éd.. Collection bleue, Montréal, Wilson \& Lafleur Ltée, 1997, $n^{05}$ 5-16, pp. 5-15, $n^{\text {os }}$ 263-268, pp. 190-195; 10, Les successions Cowansville, Les Éditions Yvon Blais, inc., 1994, nos 332-339, pp.395-417.
} 
A partir de este momento, jadiós mejoras! El legislador comienza una vorágine en la que las reformas en este campo son nefastas.

\section{El trueque de un derecho real de copropiedad contra una ilusión: la reforma de 1989}

Parece que hay acuerdo tanto en doctrina como en jurisprudencia para afirmar que la reforma introducida en $1989^{20}$ ha distorsionado considerablemente toda el área de los regímenes económico-patrimoniales, además de tener incidencias sobre las sucesiones. En el aspecto que nos concierne, como lo hemos señalado ya, el legislador deteriora ese área del derecho. Al introducir el patrimonio familiar como régimen legal imperativo, copiando una institución abandonada por el legislador de Ontario ${ }^{21}$ y reemplazada por una legislación con grandes semejanzas con la sociedad de gananciales de Québec ${ }^{22}$, el legislador de Québec olvida su propio sistema, establece ese régimen imperativo sobre unas bases jurídicas aleatorias $y$, abandonando la indivisión de los bienes a repartir, organiza un complicado sistema que termina en el reconocimiento de un crédito en favor del cónyuge cuyos gananciales son de menor valor. Una vez establecido ese régimen, decide uniformizar la terminología legislativa de la sociedad de gananciales. Al hacerlo, como ya lo hemos señalado, transforma la naturaleza jurídica de este ré gimen al hacer desaparecer el derecho real de copropiedad que cada cónyuge (o sus herederos) tenía sobre la indivisión de gananciales del otro, para dar entrada a un derecho de crédito no garantizado. Además, al relegarlo al rango de régimen legal supletorio, termina también excluyendo de la sociedad de gananciales todos los gananciales incluidos en el patrimonio familiar. Es decir que la sociedad de gananciales será aplicable solamente a los bienes que no se encuentren incluidos en el patrimonio familiar. Así pues, como el valor de las residencias familiares ha de contabilizarse para calcular el crédito (que podría llamarse de igualación) del cónyuge más "pobre» en gananciales incluidos en el patrimonio familiar, no parece que esos bienes puedan contarse de nuevo en la partición de la sociedad de gananciales.

Las modificaciones introducidas en el artículo 514 en 1989 (abandono de la indivisión para establecer un partición en valor) hubieran debido producir en toda lógica los reajustes necesarios en el artículo 515 que reglamenta una modalidad de la partición en bienes aplicable a la vivienda y otros bienes familiares, reconociendo al cón ge sobreviviente el derecho de exigir la adjudicación preferente de esos bienes familidres. Ahora bien, este artículo en su tenor entre 1989 y 1994 constituye un

\footnotetext{
${ }^{20} \mathrm{Cf}$. Loi modifiant le Code civil du Qué bec et d'autres dispositions législatives afin de favoriser l'é galité é conomique des é poux, L.Q. 1989 , c. 55.

${ }^{21}$ Cf. Family Law Reform Act, 1978, S. O. 1978, c. 2.

${ }^{22}$ Cf. Family Law Act, 1986, S. O. 1986 c. 4, ahora en R. S. O. 1990, c. F-3; para un estudio ver J.D. PAYNE, Spousal Property Rigths under The Ontario Family Law Act, Toronto-Vancouver, Batterwoths, 1987.
} 
testimonio flagrante de la incompetencia. ¿Cómo exigir que se nos atribuya un bien determinado -característica de la partición de una indivisión hereditaria- en la reclamación de un crédito? Hay pues una incoherencia en el articulado del código que nadie parece haber detectado. La jurisprudencia en este campo no se ha pronunciado sobre estas cuestiones. Si juzgamos por los comentarios del Ministro de la Justicia, en su servicio tampoco se han dado mucha cuenta de las incoherencias ${ }^{24}$. Pasemos pues a estudiar la situación actual.

\section{La consolidación de un derecho ilusorio: el nuevo Code civil du Québec de 1994}

Al entrar en vigor el nuevo Code civil du Québec el $1^{2}$ de enero de 1994, las disposiciones anteriores se encuentran bajo la nueva formulación en los artículos 481 y 482. El primero no difiere en nada del artículo 514 anterior. En ambos se ha remplazado el derecho que detenía el titular de los gananciales de pagar la parte del otro cónyuge en valor o en bienes por las expresiones en numerario o por "dation en paiement ${ }^{25}$. Ahora bien, no deja de ser sorprendente que el legislador reconozca a una parte el derecho de imponer a la otra un contrato, puesto que la "dation en paiement" está reglamentada en el código, junto con la permutación, como uno de los contratos semejantes a la compraventa ${ }^{26}$. Parece extraño que el legislador se olvide del carácter consensual de un contrato de su proprio código, que utilice una expresión impropia y que produce confusión. Probablemente quería decir que el cónyuge titular de la propiedad de los gananciales podría decidir, como ya se había previsto anteriormente, la forma de pagar a su cónyuge, ya sea en bienes o en dinero ${ }^{27}$. Sorprende que el legislador manifieste ignorancia de su sistema y de la terminología jurídica apropiada. $Y$

\footnotetext{
${ }^{23}$ Comparar en el anexo los art. 514 y 515 C.c.Q. en sus versiones de 1980 y de 1989 asi como los art. 481 y 482 C.c.Q.

${ }^{24}$ Tras la promulgación del nuevo código y poco antes de su entrada en vigencia se publicaron los Commentaires du ministre de la Justice, Tom. I y II, Qué bec, Les publications du Québec, 1993, en los que se recogen el articulado bilingüe del Código y unos breves comentarios bajo cada articulo que se atribuye el Ministro, aunque se trate de notas preparadas por diversos colaboradores. Al comentar el art 482 dice: "Cet article reprend l'art. 515 C.C.Q. (1980) et ne le modifie que pour assurer la concordance avec l'article précédent et les dispositions sur le patrimoine familial. L'article 482 prévoit le remplacement de l'expression place dans son lot par donne en paiement, plus juste dans un contexte de partage en valeur numéraire plutồt qu'en nature.» Para un análisis de esos comentarios ver D. JUTRAS, "Le ministre et le Code -essai sur les Commentaires", dans Mélanges PaulAndré Crépeau, Cowansville, Les Éditions Yvon Blais, inc., 1997, 451-486.

${ }^{25}$ Mantengo la expresión en francés por no haber encontrado en castellano un término que corresponda exactamente a este tipo de contratos, especie de permutación (ver art. 1897-1900 C.c.Ch.) pero aplicable exclusivamente al pago de una deuda. El deudor ofrece en pago de su deuda una cosa en vez de una suma de dinero o de una cosa distinta de aquella a la que el acreedor tenía derecho. Este último ha de aceptar ese cambio de objeto.

${ }^{26}$ Cf. art. 1799-1801 C.c.Q.

${ }^{27}$ Así lo reconoce el Tribunal de Apelación ver Droit de la famille -3258, [1999] R.J.Q. 643, 650, aunque utilice la expresión errónea de "dation en paiement».
} 
sorprende más aún que desde entonces la expresión "dation en paiement» comience a tener un sentido ambiguo.

Queda la problemática del artículo 482 que no es nada fácil. En efecto, esa disposición jugaba en sus versiones anteriores ${ }^{28}$ un rol importante cuando la sociedad de gananciales era el único régimen legal, pues reconocía al cónyuge sobreviviente un derecho de atribución preferente de la vivienda familiar. Ciertamente ese derecho podía ejercerse solamente cuando la vivienda era un bien ganancial y el cónyuge supérstite había aceptado la partición de esos gananciales, además de exigir el pago del excedente si el valor de la vivienda superaba el de la mitad de los gananciales a los que el cónyuge tenía derecho. No se trataba pues de un derecho absoluto, pero sí comportaba una protección razonablemente eficaz de la vivienda y otros bienes familiares.

Cuando el $1^{2}$ de julio de 1989 entre en juego el nuevo régimen legal imperativo (el patrimonio familiar), se produce entonces una distorsión con varios efectos. El primero es que el artículo 515, al haber abandonado la analogía con indivisión hereditaria y el derecho de la partición en bienes, aparece incoherente y anacrónico. Pero aún pudiendo hacer abstracción de esa realidad, hay que darse cuenta que ahora la vivienda familiar forma parte normalmente de los bienes cuyo valor han de contabilizarse para calcular el crédito de igualación de los beneficios que uno de los cónyuges podrá reclamar al otro en el contexto del patrimonio familiar. Así pues, y quizás también por casualidad como el burro flautista, el legislador además de conservar un artículo 515 incongruente en el contexto en el que se integra (la reglamentación del régimen legal supletorio, la sociedad de gananciales), lo ha vaciado de su sentido, puesto que no parece lógico que el valor de la vivienda familiar se contabilice dos veces para calcular dos créditos de naturaleza distinta. En efecto, el crédito de igualación del patrimonio familiar busca a compensar la diferencia entre los patrimonios de ciertos gananciales de los esposos, mientras que el de participación de la sociedad de gananciales tiene como finalidad la partición en valor de los gananciales de cada esposo, es decir de los gananciales residuales, o sea los que no están ya incluidos entre los bienes del patrimonio familiar.

La incoherencia aumenta cuando el artículo 482 entre en vigor el $1^{2}$ de enero de 1994, pues el legislador considera conveniente, sin mayores explicaciones, no solo eliminar la frase "placer dans son lot», que manifiesta una cierta lógica, pues ya no hay lotes al no haber indivisión, sino remplazarla por "exiger qu'on lui donne en paiement", cuyo incongruencia hemos ya señalado, puesto que se trata de un contrato. Además, para mayor confusión ese artículo precisa que para ejercer ese pseudo-derecho se

\footnotetext{
${ }^{28}$ Es decir el articulo $1267 \mathrm{c}$ de $1970-1981$ y el 515 de $1981-1989$.
} 
requiere que la vivienda familiar sea un bien ganancial (hasta aquí en ese aspecto nada cambia) y añade: o uno de los bienes que integran el patrimonio familiar. Provoca así el legislador una confusión entre los dos regímenes legales, el imperativo y el supletorio.

Esa confusión sorprende sobremanera. En efecto, en la reglamentación del patrimonio familiar, el artículo 420 permite ya al juez atribuir ciertos bienes a uno de los cónyuges al ordenar el pago del crédito de igualación que el mismo juez ha establecido. Esta norma, aunque no mencione explícitamente la vivienda familiar, permite la atribución preferente. Se comprende mal pues que haya que hacer intervenir la norma del artículo 482 para poder otorgar esa vivienda al sobreviviente cuando se trate de un bien del patrimonio familiar. Lo más sorprendente es que el legislador no se haya dado cuenta que ese artículo carece ahora de sentido, a pesar de haber añadido la mención a los bienes que forman parte del patrimonio familiar, puesto que es casi metafísicamente imposible que la vivienda familiar pueda encontrarse entre los gananciales de la société d'acquêts. La definición del artículo 415 es tan amplia que toda vivienda familiar que pueda calificarse de bien ganancial, estará siempre incluida en los gananciales que hay que contabilizar para calcular el crédito de igualación del patrimonio familiar. Por consiguiente, podemos concluir que el artículo 482 es un cascarón vacío.

Nos queda pues una sola avenida que pueda dar más sentido y una mayor eficacia a la atribución preferente, la vía sucesoria que pasamos a estudiar.

\section{Una adjudicación preferente real y aleatoria: la vía sucesoria}

La norma del artículo 856 es clara y reconoce al cónyuge del difunto el derecho de exigir que se le atribuya preferentemente la vivienda familiar que está incluida en la indivisión. Esta atribución es real y a la vez aleatoria pues teniendo en cuenta la libertad absoluta reconocida por el derecho de Québec para disponer de sus bienes por testamento, sin ningún tipo de legítima o de reserva, esa atribución preferente se aplica solamente cuando la vivienda familiar forma parte de la masa de bienes de la sucesión a la que el cónyuge pueda tener derecho.

Conviene subrayar que la finalidad de esta posible atribución preferente no es la de otorgar al cónyuge sobreviviente una parte de la herencia superior a la que le correspondería ab intestato o por testamento. El fin de este privilegio es permitir a este cónyuge que algunos bienes específicos (la vivienda familiar, los derechos que le permiten su uso y los muebles que la guarnecen) incluidos en la indivisión hereditaria se incluyan en su lote al llevar a cabo la partición sin que ello pueda traducirse en un aumento del valor de su parte, puesto que el segundo párrafo del artículo prevé el pago del excedente si lo hubiera. Como puede fácilmente apreciarse este derecho o privilegio no es de aplicación absoluta. 
Efectivamente como en el derecho de Québec existe, ya desde antes de la primera codificación ${ }^{29}$, la libertad absoluta de disponer por testamento de sus bienes sin restricción alguna en cuanto a bienes específicos se refiere, la atribución preferente no llegará a realizarse en todos los casos. Ciertamente, la reforma de 1989 ha introducido algunas limitaciones como consecuencia de la imposición legal del patrimonio familiar en cuanto al valor de esos bienes del que puede disponer por testamento, puesto que ef crédito de igualación puede exigirse a los herederos y que la obligación de pagar alimentos puede sobrevivir al deudor y ser exigida de la sucesión ${ }^{31}$. Por supuesto, si las disposiciones testamentarias tuvieran como consecuencia que el patrimonio del de cuius no pudiera cubrir las obligaciones de pago del crédito de igualación del patrimonio familiar o de la eventual obligación de alimentos, se procedería de una forma análoga a la reducción de legados ${ }^{32}$, para que la sucesión pueda pagar esas deudas. Pero ello no conduce a una atribución preferente de la vivienda ni anula el derecho de ceder sus bienes por testamento a quien se considere oportuno.

Así pues, para que esa atribución preferente de la vivienda familiar pueda surtir pleno efecto tienen que reunirse condiciones relativas al bien, es decir a la vivienda y a la persona que solicita esa atribución preferente.

\section{Condición relativa al bien solicitado: la vivienda}

Como ya se ha insinuado, esta condición es esencial: es imperativo que la vivienda familiar esté incluida en la masa indivisa de bienes de la que el cónyuge sobreviviente es uno de los coproprietarios. En caso contrario el cónyuge no puede solicitar esa «atribución preferente». Así pues, si el causante propietario de la vivienda familiar la hubiera legado a una persona distinta del cónyuge sobreviviente, auque este fuera heredero del residúo de los bienes, no podría reclamar la vivienda al no formar parte de la indivisión en la que él tiene ese derecho.

\section{Condición relativa a la persona que solicita la atribución: el cónyuge sobreviviente}

Para que el cónyuge supérstite pueda solicitar la atribución preferente no basta con que sea el cónyuge, sino que además ha de ser heredero legal o testamentario

\footnotetext{
${ }^{29}$ Cf. G. Briėre, Le nouveau droit de successions, 2 éd., Collection bleue, Montréal, Wilson \& Lafleur Ltée, 1997. $\mathrm{n}^{\circ \mathrm{s}}$ 5-11, pp. 5-10; ID, Les successions, Cowansville, Les Éditions Yvon Blais, inc., 1994, n 13, pp. 19-21.

${ }^{30}$ Cf. ID, Le nouveau..., n ${ }^{\text {os }}$ 263-264, pp. 190-191; ID, Les successions, $n^{\text {os }} 338-339$, pp. 405-417.

${ }^{31}$ Cf. art. 684-695 C.c. Q.; G. BRIÈRE, "L'obligation alimentaire survit désormais au décès du débiteur», (1989) 20

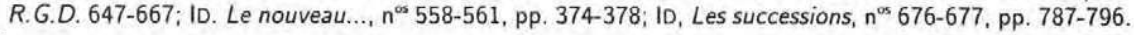

${ }^{32}$ Cf. art. 689-694 C.c. Q.; G. BRIĖRE, Le nouveau .., n n5 560-561, pp. 376-378; ID, Les successions, no 677, pp. 792. 796.
} 
universal o a título universal. Si en cuanto heredero no tiene derecho sobre la masa de bienes que incluye la vivienda familiar no le será posible, lógicamente, exigir la atribución preferente.

Además, si el cónyuge del causante hubiera sido desheredado o si el testamento le otorga otros bienes, distintos de la vivienda familiar, el artículo 856 será inaplicable a su caso.

\section{Síntesis}

Como puede verse, entre las avenidas posible para que el cónyuge sobreviviente solicite la atribución preferente de la vivienda familiar, la sucesoria es la que ofrece mejores posibilidades. Pero estamos muy lejos de una atribución absoluta y cierta puesto que todo depende de la voluntad del propietario de la vivienda que puede otorgarla por testamento a otra persona frustrando así las expectativas del cónyuge. Aun cuando el cónyuge pueda solicitar la atribución preferente, el derecho de Québec ha exigido siempre el pago del excedente del valor si la parte hereditaria (o anteriormente la de los gananciales) del cónyuge supera el valor de la vivienda que reclama.

\section{Conclusión}

Sobre el papel el Code civil du Québec parece ofrecer amplios campos de protección a la familia a través de la vivienda familiar. En teoría protege su uso durante el matrimonio y permite al tribunal ciertas atribuciones a la disolución. La vivienda puede ser utilizada como moneda de pago para los créditos de igualación derivados del régimen legal imperativo (el patrimonio familiar) o para el que se reconoce para corregir las situaciones de eventuales enriquecimientos injustos (prestación compensatoria), pero esos créditos han de existir. Parece también que en el régimen legal supletorio (la sociedad de gananciales) se podría reclamar la vivienda en pago del crédito de participación de los gananciales, pero en todas estas situaciones, cuando se analiza el derecho en su conjunto y se ponen las normas en su verdadera perspectiva, se llega a la conclusión que son fuegos de bengala.

El derecho sucesorio parece más seguro pues al menos se contempla la atribución preferente de un bien concreto, la vivienda familiar a un heredero específico, el cónyuge sobreviviente, pero también en estas situaciones estamos sobre arenas movedizas, pues ni hay garantías absolutas de que la vivienda formará parte de la mas indivisa ni tampoco de que el cónyuge sea heredero con título suficiente para reclamar la atribución preferente. La libertad absoluta de disponer de sus bienes por testamento provoca una incertidumbre completa. 
Parece que el legislador de Québec no acaba de decidirse por proteger verdaderamente la situación patrimonial de base de la familia.

Ottawa, 28 de mayo de 2001

\section{APENDICE. TEXTOS LEGALES CITADOS}

\section{CODE CIVIL DU BAS CANADA}

art. $624 \mathrm{e}$

"S'il y a postérité, ou un pére ou une mere ou les deux, ou des parents collatéraux jusqu'aux neveux ou meces au premier degré inclusivement, selon le cas, I' épouse, pour pouvoir succéder á son marị, doít renoncer á tous ses droits dans la communauté de biens ou la société d'acquéts qui peut avoir existée, entre eux, ainsi qu'á tous les droit de survie qui lui échoient parr son contrat de mariage ou par la loj, y compris le douaire; et le marj ne peut succéder á son épouse sans renoncer á ses droits dans la socié té d'acquéts, le cas échéant, ou sans retourner d'abord á la masse, comme s'il s'agissait d'un rapport fait en vertu de 1'article 700, sa part dans la communauté de biens qui a pu exister entre lui et son épouse, au cas d'acceptation de telle communauté par la succession de la femme, ou abandonner á la masse tous les droits ou avantages que peut lui conférer le contrat de mariage qui a pu exister entre eux.»

art. 700

"Chaque cohéritier fait rapport á la masse, suivant les régles ci-aprés établies, des dons qui lui ont été faíts et des sommes dont 11 est débiteur."

art. $1267 c$

"Le réglement des récompenses achevé, la masse des acquéts se partage par moitié entre les époux, ou leurs ayants droit, suivant les régles prévues au titre Des Successions pour les partages entre cohéritiers, á moins que Fépoux titulaire du patrimojne, ou ses ayants droit, ne référent désintéresser le conjoint, ou ses ayants drojt, pour la totalité ou pour une part de ce qui leur revient, en leur en payant la valeur.

Toutefois, si la dissolution du régime resulte du décés ou de Fabsencé de Fépoux titulaire du patrimoine, son conjoint peut exiger que $1^{\prime}$ on place dans son lot, moyennant paiement par lui au comptant d'une soulte, s'il y a lieu, la maison d'habitation, les meubles de ménage, l'établissement industriel, agricole ou commercial de caractére familial, qui font partie de la masse partageable. 
Á défaut d'accord entre les parties, 1'estimation des biens aux fins d'application des dispositions du présent article est faite par des experts que désignent les parties elles-mémes ou, á défaut, un juge de la Cour supérieure du district du domicile conjugal.»

\section{CODE CIVIL DU QUÉBEC 1980}

art. 514

"Le réglement des récompenses achevé, la masse des acquéts se partage par moitié entre les époux, suivant les régles prévues pour les partages entre conéritiers, á moins que $1^{\prime}$ é poux titulaire du patrimoine ne préfére désintéresser le conjoint pour la totalité ou pour une part de ce qui lui revient, en lui en payant la valeur.»

art. 515

"Si la dissolution du régime résulte du décés ou de 1'absence de l'époux titulaire du patrimoine, son conjoint peut iger que 1'on place dans son lot, moyennant, s'il y a lieu, une soulte payable au comptant ou par versements, la résidence familiale et les meubles qui sont affectés á 1'usage du ménage, ainsi que tout autre bien de caractére familial faisant partie de la masse á partager.

Á défaut d'accord sur le paiement de la soulte, le tribunal en fixe les modalités de garantie et de paiement."

\section{CODE CIVIL DU QUÉBEC 1989}

art. 514

"Le réglement des récompenses effectué, on établit la valeur nette de la masse des acquéts et celle-ci est partagée, par moitié, entre les époux. L'époux titulaire du patrimoine peut payer á son conjoint la part qui lui revient en numéraire ou par dation en paiement."

art. 515

" Si la dissolution du régime résulte du décés ou de $1^{\prime}$ absence de $1^{\prime}$ époux titulaire du patrimoine, son conjoint peut exiger que $1^{\prime}$ on place dans son lot, moyennant, s'il y a heu, une soulte payable au comptant ou par versements, la résidence familiale et les meubles qui sont affectés á 1'usage du ménage, ainsi que tout autre bien de caractére familial faisant partie de la masse á partager. 
Á défaut d'accord sur le paiement de la soulte, le tribunal en fixe les modalités de garantie et de paiement."

\section{CODE CIVIL DU QUÉBEC 1991-1994 (ACTUEL)}

art. 481

"Le réglement des récompenses effectué, on établit la valeur nette de la masse des acquéts et cette valeur est partagée, par moitié, entre les époux. L'époux titulaire du patrimoine peut payer á son conjoint la part qui lui revient en numéraire ou par dation en paiement.»

art. 482

"Si la dissolution du régime résulte du décés ou de l'absence de l'époux titulaire du patrimoine, son conjoint peut exiger qu'on lui donne en paiement, moyennant, s'il y a lieu, une soulte payable au comptant ou par versements, la résidence familiale et les meubles qui servent á fusage du ménage ou tout autre bien á caractére familial pour autant qu'ils fussent des acquéts ou des biens faisant partie du patrimoine familial.

Á défaut d'accord sur le paiement de la soulte, le tribunal en fixe les modalités de garantie et de paiement.» 